\title{
10.1590/S1414-40772018000100014
}

\section{Efeitos multiplicadores das redes de colaboração em pesquisa. Um estudo internacional ${ }^{1}$}

\author{
Denise Balarine Cavalheiro Leite \\ Célia Elizabeth Caregnato \\ Bernardo Sfredo Miorando
}

Resumo: Em todas as áreas de conhecimento os produtos de pesquisa estão a ser notados nas publicações de pesquisadores que trabalham em redes de pesquisa. Os efeitos multiplicadores das redes são vistos como uma das benesses do trabalho colaborativo, pois que ampliam os créditos de avaliação individual. Contudo, há outros elementos nas estruturas do trabalho intelectual originado nas redes que têm tanta relevância quanto o fator produtividade multiplicada. Neste artigo mostramos alguns destes elementos ou fatores multiplicadores do trabalho operado nas redes de pesquisa e identificados nos seus ecossistemas biográficos e cognitivos. Enfocamos estudos de caso de redes de pesquisa e colaboração de quatro países, Colômbia, Portugal, Uruguai e Brasil. Dentre os efeitos multiplicadores, destacamos os elementos que ligam uma rede; como e por que os pesquisadores trabalham em colaboração; os tipos de colaboração; ciclos de vida das redes; as formas de articulação; as inter-relações e o foco nas audiências para produção de conhecimento.

Palavras-chave: Redes de pesquisa e colaboração. Efeitos multiplicadores. Pesquisa internacional. Colombia, Portugal, Uruguai, Brasil.

Multiplying effects of research collaboration networks. An international study

Abstract: In all areas of knowledge, research products are being noticed in the publications of researchers working on research networks. The multiplying effects of networks are seen as one of the benefits of collaborative work, since they increase individual assessment credits. However, there are other elements in the intellectual work structures originated in networks that have as much relevance as the multiplied productivity factor. In this article we show some of these elements or multiplier factors of the work carried out in the research networks and identified in their biographical and cognitive ecosystems. We focus on case studies of research and collaboration networks from four countries, Colombia, Portugal, Uruguay and Brazil. Among the multiplier effects, we highlight the elements that connect a network; how and why researchers work collaboratively; types of collaboration; network life cycles; the forms of articulation; the interrelationships, and the focus on the audience for knowledge production.

Key words: Collaboration research networks. Multiplying effects. International research. Colombia, Portugal, Uruguay, Brazil.

Este é um artigo publicado em acesso aberto sob uma licença Creative Commons https://creativecommons.org/licenses/by-nc/4.0/

\footnotetext{
${ }^{1}$ Apoio CNPq.
} 


\section{Introdução}

Em todas as áreas de conhecimentos, e também, nas ciências humanas e sociais, os produtos de pesquisa estão a ser notados em publicações de pesquisadores que trabalham em redes de pesquisa e colaboração. O tema diz respeito à criação de conhecimento na universidade e à maneira pela qual os pesquisadores estão produzindo ciência acadêmica e inovação. Recentemente, por exemplo, Bejinaru (2017, p. 590), reafirmou as capacidades dinâmicas das universidades na sociedade do conhecimento e o benefício dos movimentos de colaboração em pesquisa, dado "o efeito multiplicador das redes de pesquisa em colaboração e coautoria".

Os efeitos multiplicadores das redes, em geral, são vistos como uma das benesses do trabalho colaborativo, pois que as publicações em coautoria tendem a multiplicar a produtividade individual, melhorando a avaliação individual dos pesquisadores. Contudo, entendemos que há outros elementos nas estruturas do trabalho intelectual que se origina das, e nas, redes que têm tanta relevância quanto o fator produtividade multiplicada.

Neste artigo, mostramos alguns destes elementos ou fatores do trabalho intelectual operado nas redes de pesquisa e identificados nos seus ecossistemas cognitivos. Para chegar a tais fatores, trabalhamos aprofundando em descrição intensiva seis redes de pesquisa e colaboração de quatro países: Colômbia, Portugal, Uruguai e Brasil. Nesses estudos, focamos a interatividade, o próprio processo de produção de conhecimento no interior das redes examinadas.

Uma cronologia breve da literatura refere que, em 2010, os cientistas procuravam a colaboração pois era do seu interesse engajar-se ao "grande projeto do século 21" (CHRISTAKIS; FOWLER); em 2011, a Royal Society de Londres referia que a colaboração em pesquisa dá acesso a variados recursos e, ao mesmo tempo, proporciona benefícios mútuos aos cientistas; em 2012, a Nature, por seu editorialista Jonathan Adams, anunciava a "ascensão das redes de pesquisa"; no mesmo ano, Wixted e Holbrook (2012) apontavam as possibilidades para a "avaliação formal das redes de pesquisa"; em 2012, nossa pesquisa, timidamente, apontava a avaliação do conhecimento produzido em redes (LEITE; LIMA, 2012); em 2014, a revista Avaliação dava espaço aos indicadores em um artigo intitulado "Avaliação de redes de pesquisa e colaboração" (LEITE et al., 2014). Assim, tendo como pano de fundo a literatura internacional e nosso interesse em avaliação participativa, foi-se construindo um conhecimento 
sobre redes de pesquisa e colaboração em parcerias nacionais e internacionais. Estudamos redes organizando-nos em rede ${ }^{2}$.

Na sequência, descrevemos brevemente a pesquisa, sua metodologia, as redes estudadas e seu ecossistema biográfico. Identificamos, depois, alguns dentre os elementos que produzem efeitos multiplicadores, tais como a liderança, a coesão, os ciclos de vida e o ecossistema cognitivo criado em cada rede através das parcerias nacionais e internacionais. $\mathrm{O}$ artigo conclui com uma breve reflexão sobre os efeitos multiplicadores das redes, considerando que a colaboração envolve elementos cognitivos e sócio-psicológicos que movem os atores. Trata-se não apenas de um capital científico multiplicado, mas, também, de um capital social e político que envolve um jogo de interesses.

\section{A pesquisa e a metodologia}

Nos primeiros estudos - da Pesquisa I, Avaliação e redes de pesquisa e colaboração: as teias do conhecimento (LEITE, 2010) -, para desenhar as conexões de rede e enxergá-las sob a forma de grafos, contamos com o apoio de uma rede interdisciplinar que ligou pesquisadores de Humanas e Sociais com pesquisadores de Comunicação e Informação e Estatística. Na ocasião, investigamos redes de colaboração de pesquisadores de excelência, no Brasil e em Portugal, das áreas de Física, Engenharia, Educação e Ciências Sociais. Escolhemos investigar pesquisadores de excelência, supondo que eles seriam responsáveis por delinear a estrutura do campo de conhecimento de suas áreas de influência (LEITE; LIMA, 2012; SFREDO MIORANDO; LEITE, 2012). Para entender as redes formadas, identificamos suas estruturas, seus nós e ligações, sua densidade e intensidade, empregando técnicas de research networks analysis (RNA). As informações obtidas, estatística e graficamente, foram complementadas por entrevistas com os sujeitos estudados em cada rede. O contato presencial com os egos - os sujeitos-chave - das redes foi esclarecedor e os grafos ajudaram a formular as perguntas sobre os processos interativos e seus resultados. A análise visual dos grafos e a construção de tabelas que forneceram os dados quantitativos de cada sujeito-chave, permitiram ver o ego em ação em

\footnotetext{
${ }^{2}$ Os autores agradecem a colaboração de Elizeth Gonzaga dos Santos Lima, Unemat, Brasil; Olga del Pillar Vasquez Cruz, Unal, Colômbia; Isabel Pinho, UAveiro, Portugal; Ernesto Dominguez, Udelar, Uruguay, responsáveis pela pesquisa e coordenação dos estudos de caso cujo resumo consta do artigo. Estes pesquisadores integram a rede produtora da pesquisa. Os estudos de caso completos farão parte da obra intitulada 'Redes de pesquisa e colaboração. Conhecimento, avaliação e o controle internacional da ciência', Editora Sulina, 2018 (in press).
} 
sua liderança de rede. Conjugando técnicas e metodologias, formulamos indicadores de interatividade nas redes com o propósito de avaliar as redes. As entrevistas esclareceram o que Van Raan (2008, p. 566) chama links metabólicos, as inter-relações e as citações mais empregadas. Dentre as curiosidades desta fase da pesquisa, destacamos que, ao apresentar aos pesquisadores entrevistados a sua própria rede, houve surpresa. Alguns pesquisadores se surpreenderam com sua própria rede e passaram voluntariamente a discorrer sobre como se dá efetivamente a colaboração.

Na Pesquisa II - Avaliação e Redes de Pesquisa e Colaboração II: produção de conhecimento e o controle internacional da ciência (LEITE, 2014) -, procuramos saber como se fazem os processos de produção de conhecimento em redes de colaboração exclusivamente nas áreas de Humanas e Sociais, Sociais Aplicadas e Ciências da Natureza, através dos estudos de caso (YIN, 2003) internacionais - Colômbia, Portugal, Uruguai, Brasil. Em cada caso estudado, concentramos nossa atenção nos contatos nacionais e internacionais de cada ego-líder e nos links metabólicos com autores de sua área de pesquisa. Procuramos visualizar os territórios acadêmicos, ou extra-acadêmicos, as hierarquias de produção em pesquisa previamente decididas ou criadas para determinadas metas e objetivos. E, ainda, quais as relações ou parcerias que o ego-líder e seus coautores mantêm com agências e agentes que financiam as pesquisas, em especial com aqueles que apareciam nos grafos de coautoria como diretamente envolvidos na colaboração, nacionais, internacionais, de formas a registrar como se faz a conexão ciência nacional-ciência internacional, os links semânticos que dão sentido ou significado à rede. Ainda sobre a metodologia, importa referir que a análise qualitativa "textocontexto" sugerida por André (1983) foi válida para adentrar realidades e recompor significados frente ao conhecimento que derivara da Pesquisa I somado ao da Pesquisa II e da revisão de literatura, originada, em sua maior parte, da chamada "grande ciência" internacional.

Neste artigo, damos ênfase aos resultados da Pesquisa II enfatizando as reflexões sobre as redes estudadas.

\section{Estudos de caso sobre redes}

Cinco estudos de casos foram descritos: Rede Redif, Rede Cipes, Rede DEyA, Rede RBBIO, Rede InovAval. Os casos estudados foram intencionalmente escolhidos pelos pesquisadores internacionais em função de serem liderados por pesquisadores de excelência, por sua familiaridade com a rede em análise, pelo seu desenvolvimento e marca nos territórios 
acadêmicos de cada país. Cada rede se reporta a uma fase do ciclo de vida das redes. A seguir, apresentamos uma síntese dos casos compilados.

Colômbia - Redif - Universidade Nacional de Colômbia (Unal)

A Rede Nacional de Investigação sobre Deslocamento Interno Forçado (Redif) foi um espaço interdisciplinar que, em aproximadamente oito anos de atividade, reuniu pesquisadores da Colômbia, preocupados pelo crescente número de famílias, provenientes do campo, que chegavam aos centros urbanos como uma das consequências mais visíveis do conflito armado então existente no país.

A Redif desenvolveu um instigante trabalho de cooperação-colaboração em torno de uma temática - o deslocamento forçado de camponeses frente à guerra e à violência do narcotráfico. Desperta atenção a colaboração que não se consubstanciou somente em coautorias, porém atingiu mais de 10 mil estudantes e desdobrou-se em 6 regiões de Colômbia, com nós de lideranças fortes formadas por investigadores de diversas universidades do país. A rede esteve sob liderança de pesquisadores da Unal da área de Ciências Sociais Aplicadas. A história da rede mostra seus antecedentes, origem e surgimento, assim como a sua extinção e morte. Os elementos analíticos centrais se referem aos aspectos acadêmicos, políticos e de vínculo que mediaram a existência da Rede e que, mesmo após sua desativação, permanecem como estrelas que ainda brilham, presentes em algumas colaborações renovadas de acordo com a re-localização da discussão sobre os impactos do conflito armado na vida nacional. Nas palavras da pesquisadora coordenadora do estudo de caso, Olga del Pillar Vásquez Cruz,

la intención de reconstruir esta experiencia está en la identificación de otros motivantes a la producción y a la colaboración entre investigadores, diferentes a los que hoy por hoy definen la eficiencia académica y que enfatizan en el número de publicaciones en revistas indexadas de alto reconocimiento, la mayoría de ellas de habla inglesa y fuera del contexto local de quienes escriben.

Portugal - Cipes - Universidade do Porto e Universidade de Aveiro

O Centro de Investigação de Políticas do Ensino Superior (Cipes) é uma associação privada que teve seu início em 1998. Este estudo caracterizou uma rede que se construiu por pesquisadores europeus. O centro de pesquisa de excelência, na avaliação da Fundação para a Ciência e a Tecnologia (FCT), erigiu-se a partir de conexões e redes individuais de investigadores de duas universidades. O centro em estudo localiza-se em Portugal. Trata-se de uma unidade de investigação com sede própria - Matosinhos -, ancorada em duas 
universidades: Universidade do Porto e Universidade de Aveiro. Desde sua origem e, em seu desenvolvimento, este grupo de pesquisa apoiou-se nas redes que constituíam o capital social do seu fundador, Professor Alberto Amaral. O crescimento se fez através de projetos de pesquisa. Foram projetos com objetivos e metas de produção de conhecimento no campo de educação superior, políticas e gestão de universidades. Adotaram-se estratégias de publicação internacional. Seus pesquisadores apresentaram trabalhos em conferências internacionais e publicaram em inglês nas revistas internacionais de referência, organizando seminários e conferências internacionais. É um centro de pesquisa consolidado que atingiu elevado grau de visibilidade internacional. Destaca-se o impacto académico de citações de trabalhos, resultados diretos e indiretos da internacionalização do grupo. A coautoria em artigos publicados caracterizam redes importantes em torno dos pesquisadores principais. Periódicos com alto fator de impacto são comumente procurados para as publicações. Além da participação com capítulos escritos para obras publicadas em outros países, outras práticas reforçam a internacionalização: a) participação nos boards das principais associações europeias de investigação na área de estudos de políticas do ensino superior e b) participação nos boards editoriais de 10 revistas internacionais nos campos abrangidos pelo grupo.

Uruguai - DEyA - Universidade de la República (Udelar)

O Departamento de Enseñanza y Aprendizaje (DEyA) do Instituto de Educación de la Facultad de Humanidades y Ciencias de la Educación, está vinculado à Universidad de la República de Uruguay. O estudo mostra as publicações e as hierarquias acadêmicas como destaque para sua estrutura e para uma rede em processo de formação. Esta rede em formação reflete o desenvolvimento do trabalho de pesquisa na área da educação, apresentado através de um dos principais espaços académicos. A partir do trabalho de pesquisadores do Departamento mencionado se analisou a forma de construção do conhecimento e a estrutura de relacionamento para gerar projetos, publicações e criar vínculos acadêmicos. Apresentaram-se os modos de associação para a geração do conhecimento que os principais pesquisadores do Departamento têm desenvolvido, institucionalmente, em forma explícita ou implícita. O Departamento de Enseñanza y Aprendizaje foi escolhido em função de que a pesquisa e o conhecimento que desenvolve contam com um reconhecimento acadêmico de nível nacional e internacional. As formas de colaboração produzidas, as áreas temáticas principais de desenvolvimento, a participação em redes internacionais e os espaços onde se vinculam dois dos pesquisadores de excelência do DEyA foram relatadas e analisadas. 


\section{Brasil - RBBIO - Universidade do Estado do Mato Grosso (Unemat)}

A Rede de Pesquisa de Biodiversidade nos Biomas Cerrado, Floresta Amazônica e Pantanal do Estado de Mato Grosso (RBBIO) está sediada na Unemat, Brasil. Colocada em contraponto com as redes de pesquisadores da Educação desta mesma Universidade, esta rede se destaca pelas parcerias internacionais, das quais fazem parte pesquisadores de Alemanha e Espanha. Destaca-se na rede a liderança forte do ego-líder e sua compreensão e entendimento das avaliações da pós-graduação no país. A rede originou-se de um grupo de pesquisa a partir das discussões realizadas no primeiro workshop dos grupos de pesquisa e pós-graduação da Unemat, no ano de 2008. Ao formar uma rede de pesquisa e pós-graduação em tema da biodiversidade dos biomas de Mato Grosso, aprovou um projeto rede de pesquisa na Financiadora de Estudos e Projetos (Finep). Os estudos começaram a se disseminar em eventos e as parcerias foram surgindo devido a um grande interesse, tanto nacional quanto internacional, sobre três biomas: Pantanal, Amazônia e Cerrado. A rede começou a se expandir de fato com as parcerias extragrupo. Um dos primeiros projetos foi uma parceria com a Espanha, para estudo da ecologia do mercúrio. Mais tarde, a rede desenvolveu uma pesquisa em cooperação com instituto internacional Maxplant da Alemanha voltado para a área de ecologia da água doce. A rede formada reúne pesquisadores intra e extragrupo, agências e empresas. Teve influência dos editais que financiavam pesquisas, com temas específicos. Ainda que atendesse demandas locais, observou-se que a rede, por suas publicações em coautorias se submete à avaliação da pós-graduação pela Comissão de Aperfeiçoamento de Pessoal de Nível Superior (Capes) e esta, em geral, não valoriza demandas locais e regionais nem o que é publicado no contexto local.

\section{Brasil - InovAval - Universidade Federal do Rio Grande do Sul (UFRGS)}

O grupo Inovação e Avaliação na Universidade (InovAval) foi formado junto ao Programa de Pós-Graduação em Educação da Universidade Federal do Rio Grande do Sul (UFRGS) em 1989, idealizado a partir desta data com a proposta de pesquisar a educação superior em parceria interinstitucional. A ação em parceria se constituiu em marca metodológica do grupo, conectando os pesquisadores experientes e aqueles em formação, dialogando em seus trabalhos e rompendo com o isolamento autoral. Ao longo dos anos, o grupo ampliou suas ações, que se organizavam em torno dos temas da pedagogia universitária, da inovação pedagógica e da avaliação institucional. Mudanças na sua composição e reconfigurações na universidade apontaram possíveis renovações e ampliações das temáticas pesquisadas para temas emergentes entre os quais se destacam a democratização da universidade na América Latina, a relação entre educação superior e educação básica, 
universidade e interculturalidade. Neste caso, foram relatadas as transformações do grupo e os incentivos à internacionalização. Procurou-se ver a rede InovAval sob o olhar dos parceiros internacionais - sujeitos respondentes - que contribuíram na trajetória do grupo e na definição/ampliação de seus embasamentos teóricos e metodológicos. As parcerias internacionais foram estruturantes na composição do grupo e na definição de seus referenciais e conceitos. Observou-se a transição dos temas inovação e avaliação para democratização, redes e modelos emergentes de universidades. A ação em parceria fomentou lógicas que promoveram participação política e deliberação horizontal, de modo a contribuir no adensamento da produção acadêmica e na formação de sujeitos numa perspectiva de democratização da universidade. A pesquisa em parceria nesta rede se apresentou como alternativa potente para o fortalecimento da formação universitária e mobilização de ideias e transformação social.

\section{Ecossistema biográfico}

O primeiro olhar dos pesquisadores, em cada estudo de caso, foi para o ecossistema biográfico a fim de esclarecer o nome do grupo em estudo que originou a rede investigada, desde o endereço, vínculos, estrutura do grupo, sua origem, surgimento, breve história, membros do grupo no ano em estudo, sua estrutura administrativa e organizacional, a forma de gestão ou autogestão do grupo.

Analisando as cinco redes de pesquisa e colaboração descritas, verificamos similaridades quanto ao ecossistema biográfico. Todas elas estão, direta ou indiretamente, vinculadas a universidades públicas: diretamente estão Redif, DEyA, InovAval e RBBIO. Indiretamente está o Cipes, única rede com autonomia e estrutura organizacional de cunho privado, porém com ligações e prestação de contas a duas universidades. As redes descritas nos casos se originaram de um espaço acadêmico como um centro de pesquisa, grupos de pesquisa, departamento de universidade, programa de pós-graduação. Apenas o Cipes tem um edifício próprio, uma sede na qual se reúnem os pesquisadores. Nos demais casos, os espaços ocupados são das instituições.

As cinco redes operam com mais de 20 membros. Observa-se uma hierarquia tênue como na Rede InovAval e uma hierarquia acadêmica definida como na Rede DEyA. Os recursos que mantém as redes provêm de órgãos públicos, agências financiadoras da pesquisa, editais de pesquisa nacionais e internacionais, como no Cipes (Comunidade Europeia), Redif (Alto Comissariado das Nações Unidas para os Refugiados - ACNUR) e instituições ou agências como na RBBIO, e também organizações não governamentais como na Redif. O volume de recursos dos editais europeus parece ser volumoso ( $€ 80$ bilhões podem ser 
distribuídos) e, ao que se indica, provavelmente permitem manutenção dos investigadores e seus espaços de autonomia. Nas redes em América Latina, os pesquisadores das redes são mantidos com seus salários universitários e bolsas de produtividade; os estudantes, com bolsas de estudo, tipo iniciação científica, como no Brasil. A maior parte dos integrantes das redes é voluntária e dedica poucas horas para a atividade de investigação dentro da rede. Os pesquisadores líderes mostram ser aqueles encarregados de acessar os editais públicos e conseguir recursos para manter as pesquisas em torno da qual os membros se organizam para produzir conhecimento.

\section{Liderança nas redes}

Sobre liderança nas redes, ocorre uma reflexão necessária. A figura do líder legítimo (WEBER, 2001) ou legitimado em seu lugar de prestígio (CAREGNATO; LEITE; SFREDO MIORANDO, 2016) cumpre um papel importante na existência e na dinâmica das redes. Em geral, trata-se de um ego-líder que se destacou pelo acúmulo de conhecimento científico em torno do tema e/ou objeto de pesquisa, evidenciando uma capacidade de ser reconhecido pelo quantum de capital científico puro que detém. Entretanto, gozar desse tipo de capital não é suficiente, já que nas redes de pesquisa investigadas, além de articular pessoas em torno dos interesses de pesquisa, o ego-líder procurou institucionalização da rede e financiamentos. Nesses termos, se a figura do líder detinha capital político, mesmo assim, precisou, também, atuar fora do campo e fora do seu centro de investigação para manter a rede funcionando, interagindo com instâncias de financiamento. O ego-líder também mostrou estar atento ao debate político da área de conhecimento atingindo outros espaços acadêmicos ou extraacadêmicos em torno do objeto pesquisado. Essa característica foi particularmente visível no caso Cipes. Seu primeiro líder havia ocupado, e ocupa, posições acadêmico-políticas relevantes - reitor, presidente de agência de acreditação e outros -, tendo, portanto, um estoque de relações nacionais e internacionais que contribuíram para o desenvolvimento da rede.

Também a liderança forte é visível na Redif que lidou com um tema que era um problema político-social de extremo desafio para a nação colombiana, já que se tratava de pesquisar e interagir com o contexto de conflito armado. Este caso descreveu muito bem o lugar das lideranças e o compromisso político em torno do trabalho de um vasto grupo de pessoas da Redif que compunham a rede e seus nós, considerados esteios da rede que se estendiam por todo o país, para além do território universitário. 


\section{Coesão das redes}

As entrevistas e os casos apresentados esclarecem que a articulação nas redes pode se fazer em torno da temática de pesquisa, da abordagem teórica, e, também, da metodologia, do financiamento, da orientação política ou ideológica, das publicações e coautorias. Examinamos nos casos estudados as pré-noções de articulação dadas pelos entrevistados com a realidade e contextos de cada rede. Verificamos que as ligações se dão entre elementos distintos e alguns dentre eles podem contribuir melhor para a coesão da rede visto que nos grupos humanos a competição é um fator permanente e pode ser estimuladora de conexões ou criar entraves à elas. Os links se estabelecem entre entidades e pesquisadores, entre mundo acadêmico e social, entre conhecimentos e estratégias. Destacamos, destas análises, para fins de estudo, os elementos que originam, induzem ou fortalecem a coesão tal como os visualizamos nas redes dos seis estudos. Alguns dentre os elementos que ligaram e fortaleceram as conexões nessas redes, nos casos estudados se encontram no Quadro 1.

\section{Quadro 1 - Fatores que favorecem conexões e coesão nas redes pesquisa e colaboração}

\begin{tabular}{|c|c|}
\hline Fatores que favorecem as conexões & Casos estudados \\
\hline Conhecimento, seus paradigmas e metodologias, as temáticas de investigação & $\begin{array}{l}\text { Cipes, Redif, DEyA, InovAval, } \\
\text { RBBIO }\end{array}$ \\
\hline Projetos que geram conhecimentos e constroem coautorias & Cipes, Redif, InoAval, RBBIO \\
\hline Estratégias (foco) para publicações & $\begin{array}{l}\text { Cipes, Redif, Inovaval, RBBIO, } \\
\text { DEyA }\end{array}$ \\
\hline $\begin{array}{l}\text { Estratégias de internacionalização, publicações internacionais, mobilidade } \\
\text { internacional de acadêmicos e estudantes, parcerias internacionais }\end{array}$ & Cipes, RBBIO, InovAval \\
\hline Parceria interinstitucional & Redif, InovAval \\
\hline Parceria internacional & Cipes, InovAval, RBBIO \\
\hline Participação dos membros da rede em pesquisas com hierarquias tênues & InovAval, Redif \\
\hline Participação dos membros da rede em pesquisas com hierarquias definidas & Cipes, RBBIO, DEyA \\
\hline Institucionalização dos grupos de pesquisa que suportam ou originam as redes & Cipes, InovAval, RBBIO, DEyA \\
\hline Força das lideranças centrais ou esteios das redes & Cipes, Redif, RBBIO \\
\hline Suporte financeiro permanente e autossustentabilidade & Cipes \\
\hline Capital social, técnico e político dos líderes e dos membros das redes & Redif, Cipes, InovAval, RBBIO \\
\hline Qualificação acadêmica dos pesquisadores & Cipes, InovAval, RBBIO, DEyA \\
\hline Interesse dos membros jovens em aprender com experts & InovAval, Redif, RBBIO \\
\hline Processos de formação e continuidade dos novos quadros & InovAval, Cipes, Udelar \\
\hline Estratégia político-social-orientada, aliando extensão-intervenção e pesquisa & Redif \\
\hline Temas de extensão e pesquisa que impactam a ética & Redif \\
\hline $\begin{array}{l}\text { Temas de intervenção social com impacto em políticas e planos } \\
\text { governamentais }\end{array}$ & Redif \\
\hline Auto e inter-apoio para desenvolvimento pessoal e sobrevivência acadêmica & Redif \\
\hline
\end{tabular}

Fonte: Autores, 2018. 


\title{
Redes, contextos e ciclo de vida
}

$\mathrm{Na}$ análise qualitativa dos casos descritos pelos pesquisadores em cada país, confirmase a literatura da área. Existe um ciclo de vida das redes mesmo que as realidades contextuais e territoriais sejam diferentes. Fazer ciência e disseminá-la em redes de pesquisa envolve publicações em coautorias, interconexões variadas entre diferentes entidades e produção e transferência de saberes e conhecimentos. Nesse caminho, por vezes difícil e tortuoso, de produzir conhecimento, é possível identificar os ciclos de vida e morte das redes. São períodos que vão da origem da rede, com pequeno número de pesquisadores, até o crescimento com muitos pesquisadores conectados e onde se verifica o auge da produção científica internacional daquela rede.

\begin{abstract}
Research Networks Life Cycle emerges when we join time dimension observing structural rearranges in $R N$. Normally, there is an initial period (discovery) with a small number of researchers. Next, an explanatory or practical potential of the idea becomes clear (invention) and is the beginning of large-scale adoption of a new theoretical framework or technological design (paradigm), which can be visualized in a large research network. In general, a network start from a small group, develop institutional or international partnership and, after that, an increase of productivity around institutions is verified (LEITE; PINHO, 2017, p. 30).
\end{abstract}

Para caracterizar os ciclos de vida, partimos do registro do ecossistema biográfico e do ecossistema cognitivo das redes, em cada caso, a partir de um dos líderes da rede e suas coautorias (Cipes, RBBIO, InovAval) ou projetamos o grafo do total das produções da rede (Redif e DEyA) no período de tempo considerado. Coletamos dados sobre as publicações e procuramos saber as estratégias de publicação em colaboração, as estratégias de divulgação dos trabalhos do grupo - congressos, journals, seminários, disciplinas acadêmicas em graduação e pós-graduação - de forma a compreender a história de cada rede e constatar seu ciclo de vida em torno à produção de conhecimento - formação, crescimento, transformação, sustentabilidade e declínio e morte ou extinção.

As redes alimentadas pelo Cipes, um centro de investigações com quase 20 anos (desde 1998), estão em fase de sustentabilidade podendo ainda crescer mais na direção apontada de procura por impactos sociais de sua produção. A Redif ativou todas as fases em seu ciclo de vida estando atualmente encerrada, ou seja, em processo de declínio seguido de extinção da rede. A rede DEyA parece estar em formação tendendo ao crescimento. A InovAval, dado ser longeva (1989), desenvolveu todo espectro do ciclo, desde a formação ao desenvolvimento e parece estar tendendo à fase de transformação, dada a mudança e ajuste de temáticas de investigação anunciadas, sem, contudo, mostrar indicações claras de haver atingido a fase de 
sustentabilidade, podendo tender à extinção. A RBBIO, criada há poucos anos, possui conexões recentes. Poderia estar vivendo as fases de formação e crescimento. Nota-se a procura de ancoragem em projetos e parcerias que sustentem seu crescimento para além dos editais que obrigam à mudança de direção dos projetos.

Estudar os ciclos de vida das redes acrescenta importantes elementos para sua avaliação. "Life cycle is an important variable to collaboration and to the planning of a research network assessment" (LEITE; PINHO, 2017, p. 30).

Em resumo, identificamos os ciclos de vida, o ciclo virtuoso de produção de conhecimento em cada rede, as condições de estabilidade das redes de pesquisa e colaboração. Uma vez identificados estes ciclos, a rede poderá ser avaliada. Para cada fase do ciclo ou o conjunto da trajetória, a avaliação poderá contemplar indicadores específicos.

\section{Ciclo de vida das redes e grupos de pesquisa:}

formação $\rightarrow$ - crescimento $\rightarrow$ - transformação $\rightarrow$ - sustentabilidade $\rightarrow$ - Crise $\rightarrow$ - declínio

\section{Ciclo virtuoso de produção de conhecimentos:}

expansão $\rightarrow$ acumulação $\rightarrow$ disseminação $\rightarrow$ revisão $\rightarrow$ inovações $\rightarrow \infty \infty \infty \rightarrow$

\section{Condições de estabilidades das redes de pesquisa:}

Inter-relações $\cong$ institucionalização $\cong$ financiamento $\cong$ avaliação $\cong$

Figura 1 - Ciclo de vida, de produção de conhecimentos e condições de estabilidade das redes

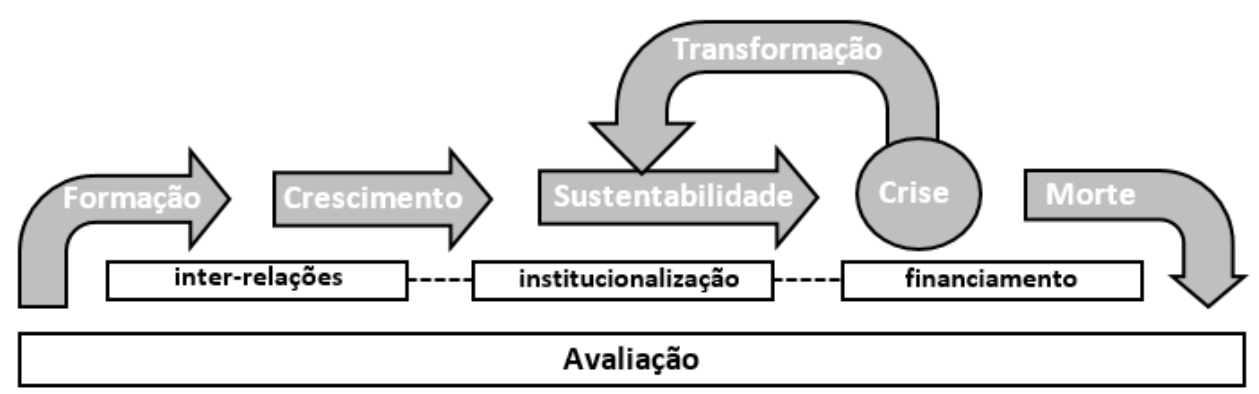

Fonte: Autores com base em ciclos de vida das redes (2017).

Ecossistema cognitivo: conhecimento produzido nas redes de pesquisa e os fins a que se destina 
Procuramos saber as estratégias de avaliação e colaboração, e de produção de conhecimento em cada rede pesquisada tentando identificar se os produtos chegam aos públicos a que se destinam. Entendemos os públicos, ou audiências, como os leitores, usuários, stakeholders ou consumidores de produtos e resultados de pesquisa acadêmica. Com certeza, as publicações, como afirma Bejinaru (2017), fazem parte das dinâmicas das universidades na sociedade do conhecimento. As redes estudadas, ligadas a estruturas universitárias públicas de prestígio, operando com financiamentos públicos, voltaram-se exclusivamente para as publicações em revistas de impacto visando atender os critérios de avaliação? As redes que pesquisamos, sendo das áreas de Humanas e Sociais, atingiram, alcançaram seus clientes, os docentes de diferentes níveis de formação, as comunidades, as escolas, outras universidades? Há evidências desse alcance?

Procuramos indicativos de resultados e impactos do trabalho em rede, primeiro nas publicações, depois nas comunidades, e se esses resultados chegaram a fazer parte da ciência internacional, nacional, regional, local. E, também, ao contrário, procuramos saber se a ciência internacional está a incidir nos links metabólicos (citações) e links semânticos (conceitos similares) que têm influência sobre a ciência que se aplica para dentro de um país, nacionalmente.

Identificamos a força das coautorias. E de sua ausência. Ao entrevistar os parceiros estrangeiros, uma das redes, InovAval, identifica as interinfluências, inclusive paradigmáticas, os sentidos e significados que as interconexões oportunizam, ou seja, os links semânticos. Em geral, o estudo mostrou que todas redes analisadas têm o objetivo de "fazer avançar o pensamento crítico e promover um entendimento informado sobre as questões vitais das políticas de ensino superior", como foi dito no estudo da rede Cipes, a rede abrangente e paradigmática de Portugal. Em cada estudo a análise voltou-se para os modelos de ciência, tecnologia e inovação (CT\&I) de cada país e para o ecossistema cognitivo de cada rede.

A seguir, tendo como referência o território-país da rede e seu ecossistema cognitivo, mostramos as análises e categorias dos produtos e resultados frente às audiências, os temas investigados e a internacionalização da rede como parte abrangente do esforço da pesquisa em colaboração.

Em Colômbia, a avaliação do Colciencias é sistemática através da avaliação de grupos de pesquisa. Porém, o estudo focou uma rede que intencionalmente não assumiu a avaliação por considerá-la um fator restritivo da sua autonomia de ação. No ecossistema cognitivo desta rede figurou um tema específico, um propósito fundamental de articulação em torno do fenômeno do deslocamento forçado, subproduto da "guerra" do narcotráfico. Fenômeno que se 
pode comparar ao dos refugiados na Europa. A Redif construiu um ecossistema formado por um time interdisciplinar de investigadores universitários, mobilizou a construção de ponencias, trabalhos individuais em vínculos solidários entre a Unal, o Colciencias, a organização não governamental Corporación e o ACNUR. A rede se diferencia pela presença de 'esteios' (estelas), lideranças descentralizadas em seis diferentes nós. Temos aqui um ecossistema cognitivo de característica diversa ao que informa a literatura - não há produção em coautoria de publicações, explícita, durante o tempo de existência da rede. Essas ocorreram após a extinção da rede. No entanto, a socialização dos papers se deu no espaço rede no qual chegaram a inscrever-se até 10 mil estudantes em seis nós regionais que se estenderam a todo país e à região conflagrada. Ou seja, o conhecimento produzido sobre a situação conflito atingiu as suas audiências!

Esse conhecimento, que se estruturou na Redif, não existia pronto na literatura. Foi construído na ação dos membros da rede e produzido em ações reflexivas de um coletivo que se expunha, individualmente, a partir de cada evento organizado. O conhecimento produzido (3 livros, 55 ponencias), não se destinava à publicação nos marcos do controle internacional da ciência ou na indexação para obtenção de méritos acadêmicos quantificáveis pelas avaliações. O conhecimento produzido na Redif era motivado pela temática e a reflexão sobre a mesma e pelo objeto - os desplazados. Em forma resumida, podemos dizer que foi construído, produzido, um conhecimento original sobre o fenômeno do deslocamento forçado (situação de guerra que obriga cidadãos à fuga do campo e da zona intraurbana sem condições de sobrevivência nas cidades), mapeamento, diversidade e particularidades do fenômeno a nível regional e territorial; as éticas, as alianças e o lugar dos profissionais; os impactos do fenômeno, a intervenção, a pesquisa aplicada a temas específicos como a reparação, o retorno e a proteção de direitos, mecanismos de restabelecimento produtivo, deficiências das ações ditas humanitárias e os trabalhos de prevenção ao deslocamento. Atingiu tal ênfase e alcance nos cenários acadêmicos e de debate nos contextos regional e nacional que veio a alcançar a política pública. Pode ser caracterizado como inovação, dada a ruptura com o conhecimento tradicional e sua localização na ecologia de saberes abrangendo saberes acadêmicos e dos desplazados. Foi notório o atingimento de audiências do Estado colombiano. Membros da rede foram requisitados pelo governo para questionar e sugerir modificações à Lei 387/97. Esta rede viveu todas as fases do ciclo de vida das redes, atingindo a fase final da extinção, contudo, dada sua relevância, sua memória foi preservada em livros e teses e estudos, como neste artigo.

Em Portugal, a avaliação dos centros é sistemática. Ocorre a cada 5 ou 6 anos. Neste modelo de avaliação de grupos e centros em CT\&I, as redes são valorizadas uma vez que a 
produção científica atende padrões internacionais e contribuem para disseminação e transferência de conhecimento e tecnologias. Sem dúvida, o ecossistema cognitivo do Cipes tem abrangência e foco em problemas de pesquisa da comunidade europeia e por suas redes se expande para outros lugares do mundo global. Pode-se dizer que, no Cipes, os produtos se incluem no paradigma da ciência internacional, nacional e regional, atendem os clientes, os contratantes dos estudos. Os resultados das pesquisas são divulgados predominantemente entre acadêmicos que acessam os periódicos em que são publicados e nas agências europeias. Dada a extensão de atendimento a estagiários internacionais, latino-americanos e outros, dada a participação dos pesquisadores em redes, como o caso das coautorias de um pesquisador-líder, mostradas em grafo, pode-se afirmar que o Cipes alcança várias universidades no mundo. As redes estabelecidas em cada projeto focam temas de análise institucional e organizacional, políticas de ensino superior, financiamento e recursos humanos na educação superior. É notória a internacionalização do Cipes (publicações em revistas de impacto, boards de agências, associações e periódicos internacionais). As redes são responsáveis pelo alargamento das citações para além do continente europeu (links metabólicos) e pelo uso de conceitos similares entre os integrantes das redes formadas (links semânticos). Entre os autores mais citados no âmbito das redes que operam com links na América, estão Rui Santiago e Alberto Amaral. Porém, em contrapartida, não se observa a citação de autores latino-americanos, mesmo aqueles pertencentes à mesma rede, nos trabalhos publicados pelo Cipes. No ecossistema cognitivo do Cipes, inclui-se a relação com o Estado. Ao pesquisar políticas públicas, os estudos influenciaram as políticas de avaliação de Portugal e do Brasil. Seu fundador, Professor Alberto Amaral foi o primeiro e até hoje é o coordenador da agência de acreditação portuguesa Agência de Avaliação e Acreditação do Ensino Superior (A3ES) e foram inúmeras as vezes em que esteve no Brasil divulgando as investigações sobre avaliação institucional das universidades tanto a convite da Associação Nacional dos Dirigentes das Instituições Federais de Ensino Superior (Andifes), quanto do Ministério da Educação e de universidades. Esta rede, dadas suas características e longevidade, estaria na fase de crescimento e tendência à fase de transformação com provável formação de novas redes e sub-redes.

Em Uruguai, o estudo analisou o Departamento de Enseñanza y Aprendizaje (DEyA) do Instituto de Educação da Faculdade de Humanidades y Ciencias da Educación da Udelar e suas inter-relações no desenvolvimento de pesquisa. O DEyA atua com pesquisa, ensino e extensão. Esta unidade acadêmica está composta por um número de pesquisadores interlocutores de fora da unidade. São parcerias insterinstitucionais e internacionais. Os principais temas das pesquisas são: enseñanza, políticas educativas, curriculum y enseñanza, 
enseñanza universitaria, dimensiones lenguajeras de la enseñanza y el aprendizaje, enseñanza y psicoanálisis, didáctica multigrado. As investigações se dão no âmbito interno da universidade e no âmbito de redes internacionais com as quais um dos pesquisadores mantém vínculos. Quanto ao conhecimento produzido, investiga-se o ensino nacional (em todos seus níveis), a inovação em campos específicos de atividade didática (inclusive linguagem de surdos) e a continuidade entre investigação, ensino e extensão. As publicações de dois pesquisadores líderes expressam uma possível atuação em rede dentro da unidade, porém, com número reduzido de coautorias. Um dos pesquisadores não está filiado à Agencia Nacional de Investigación e Innovación (ANII), e a maior parte de suas publicações são de cunho individual, autoria única. Identifica-se investigação estável e permanente em torno ao investigador, e em menor proporção se evidencia a capacidade de estabelecimento de parcerias, em especial participando de redes com pares de países vizinhos, Brasil, Argentina e Venezuela. Embora a interação e interlocução internacional exista, por meio da nomeação das diversas redes às quais o pesquisador se filia, não necessariamente se revela o mesmo na quantidade de produtos publicados no exterior. De outra parte, o outro pesquisador entrevistado está afiliado a ANII, possui uma produtividade maior no período examinado, vinculação interna com o grupo de docentes do Departamento, porém tem menor articulação internacional. Os dois têm trabalhos em coautoria, portanto formam uma rede na concepção de Newman. O caráter de sua produção, no entanto, é intensamente individual. Os dois pesquisadores indicam que a audiência a que se destina a sua produção é aquela do cenário acadêmico e da comunidade nacional de professores de todos os níveis, seja na discussão sobre os temas eleitos para pesquisa, seja na oferta de conhecimentos para as atividades de ensino e de extensão. Trata-se de uma unidade acadêmica, um departamento de um Instituto de Educação que não necessariamente se configura como uma rede em seu todo. No entanto, tendo em vista os dados levantados sobre a produção de dois líderes do departamento acadêmico, suas articulações nacionais e internacionais, sua atuação com atividades de pesquisa e a íntima vinculação da pesquisa à promoção do conhecimento por meio do ensino, esta unidade acadêmica poderia estar a estabelecer uma rede - uma rede em formação, considerando-se um ciclo de vida. Nesse sentido, o aspecto formal da divulgação acadêmico-científica por meio de publicações, sendo um item relevante, torna-se relativizado diante do impacto que esta produção causa diretamente em seus destinatários, ou seja, no interior do trabalho de formação universitária. A expansão para fora dos muros da instituição ou extra-acadêmica parece tênue, ou seja, não se distingue seu alcance. Por outro lado, as hierarquias acadêmicas típicas desta unidade e as atribuições para além da atividade de pesquisa revelam produção de conhecimento de forma individualizada atendendo a estrutura de 
responsabilidades departamentais mais do que à coautoria. Entretanto, esta unidade não está sujeita a crises em curto prazo, dada sua ampla institucionalização. No ecossistema cognitivo do DEyA, inclui-se a relação com o Estado através do atendimento aos diferentes níveis de formação docente. Observa-se que o DEyA não recebe avaliação de uma agência nacional de fomento à pesquisa, porém, está identificado pela Comisión Sectorial de Investigación Científica (CSIC), como unidade com grupos de investigação. No ecossistema identifica-se investigação intensa, sem avaliação formal do pesquisador, com grande número de ponencias (34 em 10 anos, sendo 14 internacionais, pesquisador 1; 72 sendo 3 internacionais, pesquisador 2), reduzido número de coautorias. A divulgação de trabalhos de pesquisa em ponencias, por outro lado, estabelece interlocução imediata com audiências especializadas, colégios visíveis e participativos. A rede estaria em formação com membros docentes, intrarrede, que participam das linhas de pesquisa tanto quanto membros externos, extrarrede (alguns como aprendizes) e ainda colégios visíveis e invisíveis. A rede atingiria públicos variados, acadêmicos e não acadêmicos, dado o número de resultados de pesquisa publicados em canais diversos, ressaltando-se o canal revista não científica (pesquisador 2). Esta rede em formação teria limites em alguns aspectos, como é o caso de estar ligada a um departamento acadêmico com suas hierarquias, e, desenvolver número reduzido de coautorias.

Em Brasil, no caso da rede RBBIO se manifesta uma interação com parceiros de fora da universidade com interesse explícito nas temáticas que a rede desenvolve, ou seja, conhecimento sobre os biomas do pantanal e outros. As principais temáticas de investigação pertencem aos subcampos Limnologia, Biodiversidade, Etnobiologia, Etnoecologia e Etnobotânica. Nas produções de artigos e capítulos de livros, as coautorias são parte significativa tanto com autores intragrupo quanto extragrupo, sediados no Brasil e em outros países como Alemanha e Espanha. Ou seja, esta rede foi internacional desde sua formação. O pesquisador principal, com bolsa de produtividade, recebe avaliação individual bem como seu grupo de pesquisa, através dos procedimentos Capes para pós-graduação. Aparece no estudo a audiência do trabalho de conclusão de curso (TCC), ou seja, o estudante de graduação produzindo textos dentro das mesmas temáticas - biomas Pantanal, Cerrado e Amazônia. Dentre as audiências, figura com destaque o Estado, através de seus ministérios, e as agências financiadoras, como na Rede Clima, e na Rede Bionorte. No entanto, a produção de conhecimento que se expande e atende as demandas locais (a rede tem sua origem no Pantanal de Mato Grosso) parece não atingir agência avaliadora que, segundo entrevistado, não valoriza nas suas avaliações o conhecimento local. O conhecimento de demanda local, no caso estudado, somente se sustenta quando articulado às demandas internacionais ou às demandas dos editais 
de investigação. O principal produto no entender do ego líder da rede é o livro. Então, o produto atinge a audiência, o brasileiro, aquele que conhece o português e pode ler a obra publicada. $\mathrm{O}$ livro valoriza a pesquisa e a cultura do local. $\mathrm{O}$ artigo nem sempre permite acesso. Destaque para as coautorias com alunos e orientandos que valorizam e potencializam a rede. Esta rede, em termos de produção de conhecimento e audiências, aproxima-se das características de rede Cipes, estando, no entanto, em um momento anterior de ciclo de vida, ou seja, saindo da formação e entrando na fase de crescimento.

Ainda no Brasil, o estudo de caso InovAval, mostrou o compromisso dos pesquisadores da rede a perspectiva de incidir sobre o campo educacional no sentido de abertura e ampliação do espaço para uma pesquisa de caráter público mais intenso, nem sempre valorizada pelos processos nacionais de avaliação. A rede InovAval muito cedo, em sua fase de crescimento, se constituiu com acadêmicos de vários países (Portugal, Argentina, Uruguai, Chile), ou seja, foi internacional desde sua origem sem que esta característica fosse observada pelas avaliações à época. No estudo, interrogaram-se alguns dentre os parceiros internacionais, para recompor e re-conhecer as teias de conhecimentos formadas na rede. A investigação apresentada inverteu a lógica tradicional dos demais estudos, isto é, foi ao interlocutor externo, ao extrarrede, para conhecer a teia de conhecimentos que influiu nos membros intrarrede. As temáticas que interessaram ao grupo na fase de crescimento, e constituíram as redes com trocas de conhecimentos, foram: avaliação institucional, pedagogia universitária, políticas e gestão da educação superior, ensino-aprendizagem e avaliação. As avaliações incluíram as publicações de resultados de pesquisa em periódicos, livros, eventos (Fórum Social Mundial) contabilizados pelas agências de fomento e avaliação (Capes e Conselho Nacional de Desenvolvimento Científico e Tecnológico - CNPq), e os pesquisadores credenciados em programas de pósgraduação e bolsistas de produtividade CNPq. As trocas e intercâmbios foram valorizadas. Parceiros de outros países entrevistados confirmaram a contribuição do trabalho em rede para valorizar outros conhecimentos, para além dos acadêmicos, outros métodos de busca ou metodologias não tradicionais, a prática da interdisciplinaridade, e a relevância do conhecimento, no dizer de entrevistado, "esquecido na Europa ou Portugal - a relevância social, cultural e política do conhecimento que estaria hegemonizado pelo econômico”. Na rede, além das influências acadêmicas tradicionais (leitores das publicações - livros, artigos, apresentações em eventos e Salões de Iniciação Científica -, orientandos, estudantes, docentes investigadores extrarrede, agências de fomento e avaliação), estabeleceram-se links metabólicos e semânticos. Ou seja, a rede influenciou audiências externas, de outros países, que enviaram estudantes e docentes para estágios de graduação, pós-doutorados e outros, para atuar junto a pesquisadores 
do grupo/rede. Foram inúmeras as coautorias, diretamente pela ação da parceria, no nível de atuação coletivo, colaborativo e intersubjetivo, em questões vistas como fundamentais para o avanço do conhecimento e desenvolvimento de novas problemáticas, como a formação do sujeito político dentro das universidades. Trata-se de uma rede que dialoga com "o que é" a educação superior, se autoavalia, e dialoga com "o vir a ser" na relação com seus objetos de investigação. Seu objetivo é a investigação e a formação de sujeitos, especialmente no meio acadêmico, tanto quanto possível, fora da esfera hegemônica tradicional das universidades no que tange ao aspecto da formação crítica, política. Porém, também é uma rede que obedece a tradições acadêmicas no sentido da sua estrutura, organização e divulgação do conhecimento com artigos em revistas indexadas e livros com avaliação Qualis Capes. Esta rede estaria, em seu ciclo de vida, na fase de transformação podendo tender às fases de crise ou voltar à fase de desenvolvimento.

\section{O ecossistema cognitivo e os efeitos multiplicadores}

A ciência é um sistema interconectado no qual se fazem ligações entre pesquisadores, publicações, grupos de pesquisa e instâncias acadêmicas com o fim de produzir e transmitir conhecimentos (VAN RAAN, 2008, p. 566). O sistema se auto-organiza em torno de links metabólicos, como as citações, e links semânticos, como os conceitos similares, que conectam todos esses entes e afetam e causam interinfluências. Ou seja, existem redes que fazem a ciência acontecer e existem fatores ou elementos que acentuam os efeitos multiplicadores das redes.

O conhecimento privilegiado pelas redes estudadas, a análise de seu ecossistema cognitivo, antes de qualquer parâmetro multiplicador, destaca-se pelo foco em atividades de pesquisa que resultam em produtos/resultados publicados (todas as redes) e pelos impactos do conhecimento produzido sobre as políticas públicas ou sobre políticas de agências de Estado (RBBIO, Cipes, Redif), bem como pelas interligações/interações que moldaram as comunidades de investigação internacionalizadas (Cipes, InovAval, RBBIO) ou aquelas que atuaram em escala nacional, regional (Redif, DEyA). As publicações dos membros das redes estão nos marcos do controle internacional da ciência, ou seja, foram endereçadas para periódicos com indexadores aceitos como relevantes pela comunidade de investigadores internacional para obtenção de méritos acadêmicos quantificáveis pelas avaliações, com exceção da rede Redif que recusou a avaliação da agência colombiana. A rede Redif não fez opção pela avaliação temendo perder sua autonomia de ação. Há que se confirmar que os principais interlocutores das autorias e coautorias pertencem ao meio acadêmico, já que o 
conhecimento é divulgado em formato de publicações em periódicos, em eventos e em livros, portanto, primordialmente com vista aos pares acadêmicos e sob a pressão e controle das avaliações (Cipes, RBBIO, InovAval). Diga-se que em dois países, Brasil e Uruguai, ainda não há avaliação formal de redes e/ou grupos de pesquisa. Em Portugal e Colômbia (e também iniciando em Uruguai), a avaliação de grupos de investigação está associada à obtenção de recursos.

Verificam-se diferenças entre as redes no que diz respeito aos auditórios mais amplos com os quais se relacionam ou aos quais dirigem os seus discursos, ou seja, para quem falam, para além das editorias dos periódicos em que publicam artigos e das respostas aos quesitos de avaliação das agências nacionais de avaliação. No caso do Cipes, há uma discussão de envergadura sobre o ensino superior, suas instituições, suas formas de avaliação, bem como sobre a internacionalização da educação superior. Os produtos das pesquisas, possivelmente, integram as políticas estatais para a educação superior em Portugal. A Redif surgiu da intencionalidade de trazer à tona um problema social de uma nação tornando-o objeto de conhecimento e de visibilidade para discussão pública na academia e nos polos regionais, mas, também, teve a finalidade de incidir sobre políticas públicas nacionais frente à questão objeto. Nesse caso, tratando-se de um contexto de sofrimento humano, é possível trabalhar com a hipótese de que o vasto grupo constituído para o trabalho em rede, voltado para a ação de intervenção social, ao estabelecer o acolhimento e interlocução com as vítimas, atingiu as audiências diretamente interessadas. Dessa forma, esta rede estaria sendo útil ao Estado para que armasse suas políticas de enfrentamento da questão. Foi importante para as pessoas em situação traumática porque orientou expectativas. De outra parte, também estava interagindo em campo com o conhecimento que era um produto ou subproduto da pesquisa acadêmica, problemática que havia sido anteriormente investigada e, ao mesmo tempo, ampliava este conhecimento a partir da produção de conhecimento baseada em um tipo de intervenção social intencional. Dado seu caráter peculiar, esta foi a única rede cuja extinção foi anunciada.

Com relação com à capacidade de intervenção das redes estudadas em termos de sua produção e atividades, nota-se o efeito multiplicador em resultados de investigação que: (1) referem-se ao campo universitário, com a produção de efeitos e impactos sobre a melhoria das atividades de ensino e extensão (todas as redes); (2) podem atingir a formulação de políticas institucionais (algumas redes); (3) junto às ações dos membros das redes, atingem ao campo político estatal com a repercussão na formulação de políticas e programas estatais para ensino superior e para todos os níveis de ensino, para o conhecimento e a sustentabilidade da biodiversidade bem como da sustentabilidade e administração de direitos da população 
(Portugal, Uruguai, Brasil, Colômbia); e (4) atingem ao campo social mais amplo na medida em que há atuação junto a populações por meio da escuta e do registro sobre direitos humanos e sociais, como se pode ver no estudo de Colômbia. Nesse caso, uma rede intencionada pode, até mesmo, contribuir para a introdução de transformações no cotidiano das pessoas.

A produção do conhecimento nas redes intencionalmente estudadas - com vínculos à sub-área Educação, incluindo estudos de caso em Ciências Humanas e Sociais, Sociais Aplicadas e Ciências da Natureza - está vinculada a uma perspectiva de incidência sobre a realidade social. É uma decorrência do movimento das redes em direção ao social que passa pelo contato com a esfera política, cujas tomadas de decisões as pesquisas estão a subsidiar. A aplicação do conhecimento produzido está mediada por trocas e intercâmbios no espaço público, nacional e internacional.

\section{Reflexões conclusivas}

A falta de atenção das avaliações regulatórias às especificidades das redes de colaboração em pesquisa, a suas funções vitais, permite que elas, dependendo do ciclo de vida em que se encontram, desfaçam-se, às vezes, por falta de suporte necessário. Podem ocorrer desequilíbrios entre autogestão, financiamento e interesses dos investigadores que impedem a estruturação dos tempos e espaços necessários ao bom desenvolvimento das redes. Superar essas lacunas para evitar a morte precoce das redes de colaboração, formais ou informais, demanda, então, verificar quais os processos de coesão, as práticas necessárias para manter a rede viva. Ao que vemos no estudo, os processos de coesão se vinculam primordialmente à temática de investigação que atrai os pesquisadores. Depois, a coesão das redes pode ser motivada por uma problemática social que repercute a subjetividade ético-política. Ainda, a coesão das redes se constrói no dia a dia da atuação conjunta e constante no trabalho acadêmico de produção do conhecimento.

Nos movimentos do ciclo de vida, o conhecimento produzido, a ciência construída, pode seguir a sequência da expansão, acumulação, disseminação, revisão e atingir a fase de inovações em uma possibilidade que tende ao infinito, caso a rede consiga afastar-se das crises, o que confirmaria os efeitos multiplicadores das redes. Nos movimentos do ciclo de vida, a mudança e a rapidez operam sobre o conhecimento, capital nem sempre tangível ou materializado. No século das redes de pesquisa, o conhecimento está a ser rapidamente produzido, disseminado e colocado em disposição aos mercados. No entanto, no âmbito acadêmico, o conhecimento produzido para além das publicações e seus mercados se aplica diretamente à resolução de 
problemas, às vezes emergentes e cruciais como o são aqueles da área da saúde, da educação, da economia e das consequências da guerra, como se constatou em um caso estudado.

O conhecimento produzido em todas as áreas do saber, em um mundo conectado, aplicase e se destina ao bem-viver da humanidade. Transforma-se para traduzir a ciência do laboratório em formas de tecnologia para atender necessidades técnicas da sociedade. Quando falamos em redes, falamos de uma sociedade na qual a colaboração pode ser mecanismo multiplicador para acontecimentos disponíveis à inclusão da pesquisa acadêmica no mundo da ciência internacional, o que seria o óbvio, e no mundo social e político quando a pesquisa acontece nas áreas de Humanas e Sociais. Como bem se observa nos estudos de caso coletados, é possível trabalhar em redes de pesquisa e colaboração que respondam ao contexto social, econômico e político que atravessa uma sociedade, marcando produtos que se destinam a audiências determinadas, sem estar necessariamente submetidos ao direcionamento de um marco de sistemas competitivos de medida e classificação. É possível, igualmente, realizar desta forma, pari passu com a investigação, a função histórica da universidade como um espaço de debate, de crítica e de construção influente nas políticas públicas.

Por outro lado, quando nos reportamos a um contexto-mundo desgastado política e socialmente, as disparidades, injustiças sociais e ambientais afloram em todos os lados. Populações inteiras estão marginalizadas pela falta de conexões, praticamente excluídas da sociedade da informação. Quando tratamos de redes parece que falamos de uma outra sociedade, uma sociedade sem exclusão. Entendemos que as redes de pesquisa e colaboração podem ser mecanismos para acontecimentos disponíveis à inclusão no mundo da ciência, para todos e todas, dado seu caráter multiplicador.

A associação entre pesquisadores em redes de pesquisa e colaboração com finalidades de expansão, acumulação, disseminação e revisão de conhecimentos e inovações, ativa um capital simbólico que pode ser previsto em seu valor científico, social e político.

A RN (Research Network) creates collaborative schemes that are based on a predictable symbolic capital, a capital that is at the same time scientific and social. Members of the network may not be aware of this purpose, but it embodies the idea of symbolic profit, resulting from trade-off of shared benefits and risks. This is a result, in terms of symbolic capital, i.e. a capital in cognitive basis, supported on knowledge and recognition a distinctive and honorable capital (LEITE; PINHO, 2017, p. 32).

Afinal, o conhecimento, a inovação, ambos produtos resultantes de redes de investigação, para quê e a quem servem senão para multiplicar efeitos, incluir e tornar o mundo menos injusto? 


\section{Referências}

ADAMS, Jonathan. The rise of research networks. Nature, London, v. 490, p. 335-336, out. 2012.

ANDRÉ, Marli Elisa Afonso. Texto, contexto e significados: algumas questões na análise de dados qualitativos. Cadernos de Pesquisa, São Paulo, n. 45, p. 66-71, maio 1983.

BEJINARU, Ruxandra. Dynamic capabilities of universities in the Knowledge Economy. Management Dynamics in the Knowledge Economy, Bucharest, v. 5, n. 4, p. 577-595, 2017.

CAREGNATO, Célia Elizabete; LEITE, Denise Balarine Cavalheiro; SFREDO MIORANDO, Bernardo. Pesquisadores e legitimidade científica no campo da educação. Linhas Críticas, Brasília, v. 22, n. 47, p. 189-209, jan./abr. 2016.

CHRISTAKIS, Nicholas A.; FOWLER, James H. O poder das conexões. Connected. Rio de Janeiro: Elsevier, 2010.

LEITE, Denise. Avaliação e redes de pesquisa e colaboração: as teias do conhecimento. Porto Alegre: UFRGS; CNPq, 2010. Projeto Pesquisa.

LEITE, Denise. Avaliação e redes de pesquisa e colaboração II: produção do conhecimento e o controle internacional da ciência. Porto Alegre: UFRGS; CNPq, 2014. Projeto Pesquisa.

LEITE, Denise; CAREGNATO, Celia Elizabete; LIMA, Elizeth Gonzaga dos Santos; SFREDO MIORANDO, Bernardo; PINHO, Isabel; BIER, Priscila. Avaliação de redes de pesquisa e colaboração. Avaliação, Campinas; Sorocaba, v. 19, n. 1, p. 291-312, ma. 2014.

LEITE, Denise; LIMA, Elizeth (Org.). Conhecimento, avaliação e redes de colaboração. Produção e produtividade na universidade. Porto Alegre: Sulina, 2012.

LEITE, Denise; PINHO, Isabel. Evaluating collaboration networks in higher education research. Drivers of excellence. New York: Palgrave MacMillan, 2017.

ROYAL SOCIETY. Knowledge networks and nations. Global scientific collaboration in the 21th century 2011. London: The Royal Society, 2011. Disponível em:

<https://www.snowballmetrics.com/wp-content/uploads/4294976134.pdf>. Acesso em: 5 jan. 2018.

SFREDO MIORANDO, Bernardo; LEITE, Denise. Mapeamento das redes de colaboração: detectando inovação e mudanças nas teias de conhecimento. In: LEITE, Denise; LIMA, Elizeth (Org.). Conhecimento, avaliação e redes de colaboração. Produção e produtividade na universidade. Porto Alegre: Sulina, 2012.

VAN RAAN, Anthony F. Scaling rules in the science system: Influence of field-specific citation characteristics on the impact of research groups. Journal of the Association for Information Science and Technology, West Sussex, v. 59, n. 4, p. 565-576, 2008.

WEBER, Max. A "objetividade” do conhecimento na ciência social e na ciência política. In: WEBER, Max. Metodologia das ciências sociais. 4. ed. São Paulo: Cortez; Universidade Estadual de Campinas, 2001.

WIXTED, Brian; HOLBROOK, Adam. Environmental complexity and stakeholder theory in formal research network evaluation. Prometheus, Abingdon, v. 30, n. 3, p. 291-314, sep. 2012.

YIN, Robert. Estudo de caso. Planejamento e métodos. 2. ed. Porto Alegre: Bookman, 2003. 
Denise Balarine Cavalheiro Leite Universidade Federal do Rio Grande do Sul | Faculdade de Educação | Programa de Pós-Graduação em Educação Porto Alegre | RS| Brasil | Contato: denise.leite@hotmail.com.br

(iD) http://orcid.org/0000-0002-9855-572X

Célia Elizabete Caregnato Universidade Federal do Rio Grande do Sul | Faculdade de Educação | Programa de Pós-Graduação em Educação Porto Alegre | RS | Brasil | Contato: celia.caregnato@gmail.com (iD) http://orcid.org/0000-0002-9326-590X

Bernardo Sfredo Miorando Universidade Federal do Rio Grande do Sul | Faculdade de Educação | Programa de Pós-Graduação em Educação Porto Alegre | RS | Brasil | Contato: bernardo.sfredo@ufrgs.br (iD) http://orcid.org/0000-0002-7556-1684

Artigo recebido em 8 de janeiro de 2018 e aprovado em 9 de janeiro de 2018. 